\title{
Research and Education of Lighting Technology at the Slovak University of Technology
}

Abstract. Goal of the paper is to present approaches and solutions for organization of the educational process in light and lighting at the Slovak University of Technology as a case study with generalized outcomes that can be applied in other universities or countries. The paper aims to inspire and to draw attention on education in lighting and the necessity to exchange knowledge and experience of professionals responsible for eduction, what is nowadays felt as an underestimated topic.

Keywords: lighting technology, light \& lighting, lighting education, lighting engineering

\section{Introduction}

Continuity and future of expertise in light and lighting cannot exist without proper education. Quality of education has paramount importance in the lighting society and it has direct influence to the level of personnel and lighting business in its complexity [1].

In the former Czechoslovakia, lighting technology is tought since a century ago (Fig. 1). Establishment of large size enterprises for manufacturing of lamps and luminaires in second half of the 20th century enhanced the necessity of education in the field. In the period of $1990-2000$ the education in lighting had to go through transformation and recently it is being continuosly improved institution to institution although the process today lacks a nationally coordinated actions.

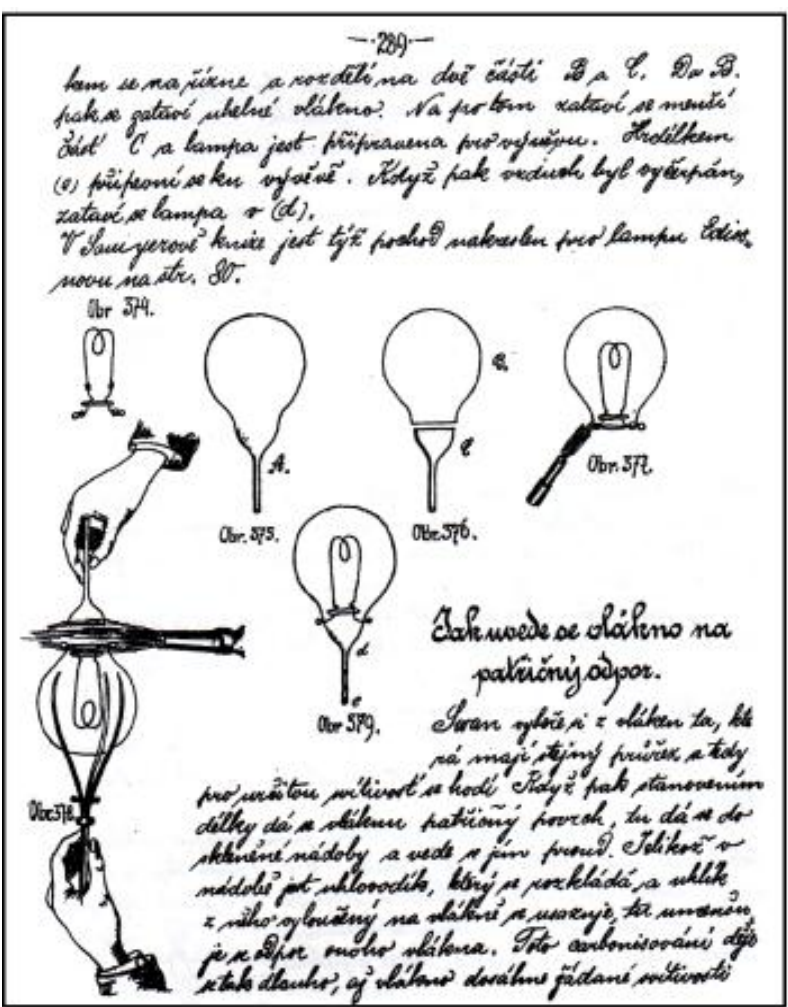

\section{Background}

Education in lighting needs to be understood as a service on different levels. Yet at the elementary school it is important to teach pupils not only about the essence of light and principles of lighting within physics but also to understand the basics of lamps, luminaires and lighting systems which are necessary for everyday life. On the leve of secondary school the fundamentals of lighting technology, practical lighting and excercises in measurements are tought as part of a subject on electrical equipments or power engineering. Unfortunately, interest of students on admission to professional secondary schools rapidly decreased though they are wanted by lighting equipment producing companies for different positions like luminaire assemblers, laboratory technicians etc.

Emphasize is obviously put to the university level of education, now in three degrees: bachelor, master and doctoral. Structure of subjects depend on the faculty orientation. Lighting technology is mainly tought at faculties of electrical engineering, daylighting at faculties of civil engineering and both partly at faculties of architecture. Minor topics are also tought at other type of faculties.

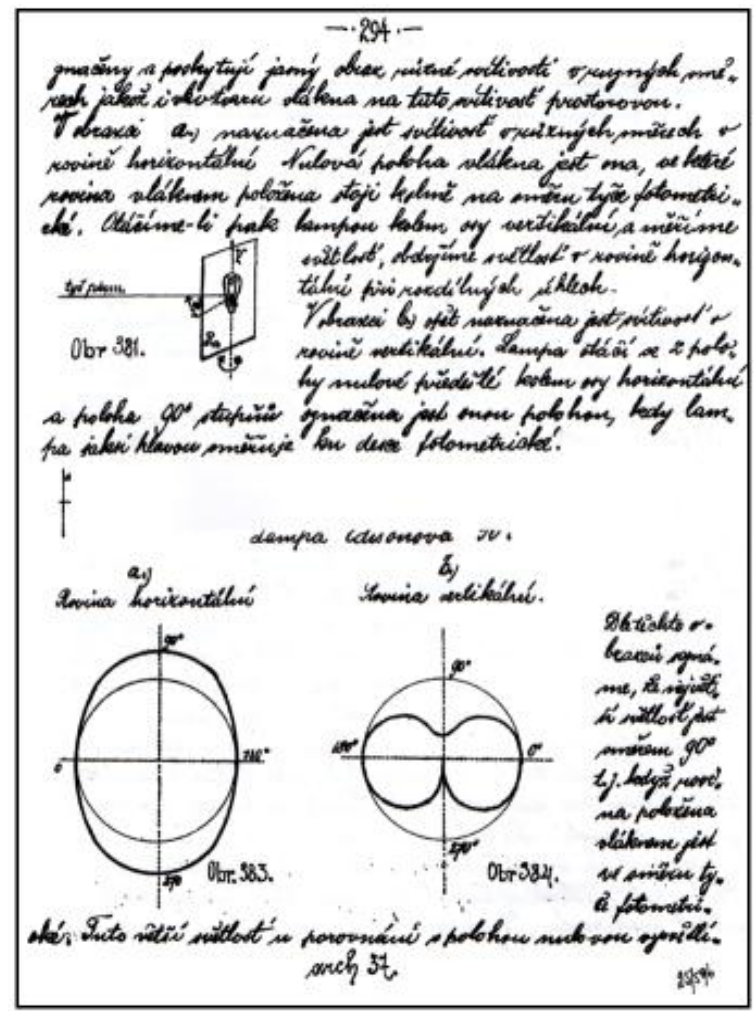

Fig.1. Two pages from the historical textbook, 1894 [2]

Between faculties of the same type there are also significant differences depending on the orientation of the particular university. Unique conditions are at the Slovak university of technology where the lighting technology is tought as a specialization and several subjects on lighting are provided for students of the bachelor and master levels 
as like as Lighting technology, Theoretical photometry and colorimetry, Measurement of light and colours, Light sources and ballasts, Luminaires, Lighting systems, Lighting applications and others. For the PhD. level there are specifically dedicated subjects for in-depth study. Currently the curricula have been improved within the periodical accreditation of universities. Alumni are wanted as lighting designers, lighting experts, lighting engineers and significant manufacturers are also sought for $\mathrm{PhD}$. level experts for their research and development centres.

Post-gradual education is not less important. Slovak lighting society cares about further education of experts not only by organising seminars and conferences but also providing regular lighting courses with respect to the needs of lighting practice. Basic level courses are intended for traders, vendors and shopping assistants without professiona background while master and expert levels are expected to enhance the horizons of knowledge of senior professionals. However, the well-built system of post-gradual education is insufficient to ensure the appropriate level of expertise on the market concerning dealers of cheap LED-based lighting products of doubtful origin, who are newcomers in lighting, lack even the basic fundamentals and are not interested to spend any time and efforts for education. Today this is the major problem of the lighting society.

Quality of education does not depend only on theory, practical training is essential as well. Photometric laboratories at universities and research centres providing the professional education meet the strictest criteria. Besides commercially available equipment and instruments the laboratories possess also unique prototypes of instrumentation constructed by the professional stuff and with the contribution of students who learn this way to develop original solutions.

\section{Education of lighting engineers}

Slovak University of Technology (STU) in Bratislava takes the main role in this process. Lighting engineer is prepared as a complex professional in lighting, provided by several subjects on lighting within a specialized study orientation Lighting Technology. There are also other study programmes dealing partly with lighting. Structure of departments and institutes of STU involved in education of lighting subjects is depicted in Figure 2.

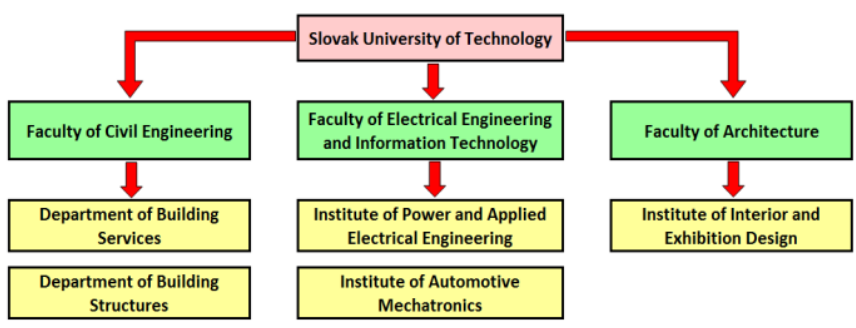

Fig.2. Structure of departments and institutes of the Slovak University of Technology in Bratislava involved in education of lighting subjects

The study programme on Lighting Technology is established at the Institute of Power and Applied Electrical Engineering, Faculty of Electrical Engineering and Information Technology. Detailed description of this study programme is below. Besides, the Institute of Automotive Mechatronics provides a specific subject in master course Lighting Systems for Automobiles dealing with automotive lighting. At the Faculty of Civil Engineering, two departments are dealing with lighting issues: daylighting is tought at the Department of Building Structures and lighting systems as part of the technical equipment of buildings is tought at the Department of Building Services.

Faculty of Architecture provided a subject on Lighting in Design and Architecture, which is now discontinued. However, workers of the faculty are active in research and practical engineering concerning floodlighting.

Faculties outside STU provide mostly overview subject on lighting only, or in some cases few subjects of this orientation. Nevertheless, students interested in the field can choose proper topic of their bachelor, master or PhD. thesis and individually immerse into more depth of this field. Study orientation in lighting at STU yearly releases $10-15$ alumni. However, not all of them stay to work in the field they studied. Yearly $2-4$ internal PhD. students and a number of external PhD. students are tought. PhD. students also help with the education and assist in laboratory and seminar exercises.

At Slovak University of Technology composition of subjects slightly varied in last two decades. This year the university is obliged to go through the re-accreditation process and thus new study structure has been prepared. It is expected, in case of successful accreditation, that the new structure comes in force from 2016. Lighting Technology will be then a self standing study programme in master level. Currently it is just a study orientation in the study programme Electrical Power Engineering. However, it will still be established on the knowledge base of power engineering. In this paper the focus is on the new study programme in lighting. Subjects of this new study programme are listed in Table 1 together with topics of these subjects - concerning lectures; topics for seminars and labs follow the theory but they are slightly different. All subjects are divided to 2 hours of lecture and 2 hours of exercises per week, having 12 weeks of semester in total. It is also useful to mention some of the former or discontinued subjects tought nowadays or few years ago.

Theoretical photometry and colorimetry and Measurement of light and colours are now two subjects that are merged in the new programme (see the subject Photometry and Colorimetry in Table 1). Reasons are only in limitation of the number of slots for subjects and passing priority to application issues in lighting.

Lighting Applications is a new subject with a new content which has not been previously tought at all or only in a limited extent.

Subjects like Physical Fundamentals of Light Sources, Construction of Luminaires, Optoelectronics, Light and Optics are discontinued since few years ago.

Other subjects have been heavily renovated what concerns the topics and contents. The knowledge and experience transferred to students reflect the current state-of-the-art in the field, research and development carried out at universities, academies, research centres, CIE, standardization institutes and of course in the industry.

In the doctoral (PhD.) degree there are also few subjects which are tought individually. Students themselves study in depth specific topics close to their thesis title or needed for the highest level of expertize. Students prepare a brief report on the agreed topics and discuss with supervisor questions in stated problems. The current two subjects are entitled Photometric measurements of lamps and luminaires and Special Lighting Systems. Within the PhD. study, emphasize is given also to individual study of CIE Publications and technical standards. In the new study programme curricula, there are no specifically entitled subjects focused on lighting but in fact the current approach is kept untouched. 
Table 1. Bachelor and master degree curricula of the new study programme Lighting Technology at the Slovak University of Technology

\begin{tabular}{|l|}
\hline \multicolumn{1}{|c|}{ LIGHTING TECHNOLOGY (Bachelor) } \\
\hline Radiant quantities and units \\
Sensors of radiation \\
Photometric quantities and units \\
Incandescent light sources \\
Discharge light sources \\
Luminaires, components and accessories \\
Measurement of light and colours \\
Lighting systems design \\
Basic lighting calculations \\
Fundamentals of interior and exterior lighting \\
\hline
\end{tabular}

\section{UTILIZATION OF ELECTRICAL ENERGY (Bachelor)} (Part of the subject)

Ecodesign in lighting engineering

Energy labelling of light sources

Waste from lighting equipments

Energy audit and lighting audit

Energy performance of buildings

\section{PHOTOMETRY AND COLORIMETRY (Master)}

Physical nature of light. Physical principles of light emanation: black body radiation, electrical discharge in gas and luminiscence. Light spectrum. Radiant quantities and units.

Human eye and vision. Fundamentals and photometry of photopic, scotopic and mesopic vision. CIE standard photometric observer. Photometric quantities and units.

Interaction of light with environment. Spatial charasteristics of illumination.

Glare: physiologic fundamentals, classification, assessment systems, prevention

Colorimetric systems. Grassmans law. Trichromatic coordinates. Colorimetric spaces RGB, Yxy, $L^{*} a^{*} b^{*}, L^{*} u^{*} v^{*}$. Light colour. Colour rendering.

Metrology. Legislation in the field of metrology. Basic principles and methods in photometry and colorimetry.

Principles and features of measuring instruments and equipments. Spectrophotometry vs. integral photometry.

Measurement of luminous flux, luminous intensity, illuminance and luminance. Measurement of spatial characteristics of illumination.

Goniophotometry. Measurement planes. Measurement of luminous intensity distribution curves. Photometric data exchange file formats - LDT and IES specific formats.

Measurement of reflectance, transmittance and absorptance. Measurement of retroreflection.

Spectral and integral measurements. Colorimetric measurements.

Accuracy of measurements. Sources of errors and deviations Uncertainity of photometric and colorimetric measurements.

\section{LIGHT SOURCES AND BALLASTS (Master)}

History of lamp production

Incandescent lamps, Halogen lamps

Linear and compact fluorescent lamps, induction lamps

Low pressure and high pressure sodium lamps

High pressure sodium lamps

High pressure mercury lamps

Metal halide lamps

LED lamps, Minor lamp types

\begin{tabular}{|l|}
\hline \multicolumn{1}{|c|}{ LUMINAIRES (Master) } \\
\hline Classification and labelling of luminaires \\
Morphology of luminaires \\
Basic parameters and characteristics \\
Design and calculation of optical components \\
Electrical parts, components and requirements \\
Construction of luminaires \\
Requirements to protection class \\
Thermal management \\
Specific requirements to selected luminaire types \\
Measurements and testing of luminaires \\
\hline
\end{tabular}

LIGHTING EQUIPMENTS AND SYSTEMS (Bachelor)

Quantitative and qualitative parameters of illumination

Calculation methods for parameters of illumination

Glare, its assessment and prevention

Maintenance of lighting systems and maintenance factor

Home lighting

Illumination of social premises

Lighting of workplaces

Shop lighting

Sports lighting

Public lighting

Tunnel lighting

Floodlighting

Emergency lighting

Lighting design and lighting project

\begin{tabular}{l} 
LIGHTING APPLICATIONS (Bachelor) \\
\hline Daylighting of buildings and light guides \\
Non-visual effects of light \\
Phototherapy, SAD syndrome and treatment by light \\
Photobiological safety \\
Desinfection by means of optical radiation \\
Photosynthetic applications \\
Influence of lighting to the ecosystem \\
Obtrusive light, its assessment and prevention \\
Integral lighting of work machines \\
Light and imaging technologies, photoelectronics \\
Decorative and festive lighting, lighting for entertainment \\
Stage lighting \\
Lighting for signalling and transport \\
Lighting in means of transportation \\
Regulation and control of daylight and artificial lighting \\
\hline
\end{tabular}

\section{Research topics of interest}

$R \& D$ activities are based on background of the workplaces, personal interests of professors and researchers and are binded with research priorities discussed in CIE and standardization institutes. Framework for research is laid down also by project grants. Research topics of interest is listed briefly below:

- Road lighting (methodology, energy performance, mesopic vision etc.)

- Energy performance of lighting in buildings

- Maintenance factor of lighting systems

- Home lighting

- Electrical parameters of lighting networks

- Illumination of workplaces

Recent granted research projects (selection):

- VEGA 1/0988/12 Energy efficiency of lighting systems in buildings

- VEGA 1/1100/12 Smart grid as part of power distribution networks - new measurement methods and consumption control methods

- ITMS 26220220150 Research Centre of Light and Lighting Technology 


\section{Infrastructure}

Photometric and affiliated laboratories are equipped with inherited older equipment as well as with the most advanced technologies. Industrial research centre is equipped with modern instrumentation. Workplaces are well equipped also for study of electrical parameters as lighting is meant as electrical lighting. Equipments and instruments are used for all purposes, from education through research to contracted commercial testing and measurements.

a) Slovak University of Technology (Figs. 3 \& 4): Laboratory of lighting equipments consist of several rooms and amenities. The laboratory is accredited for testing of lamps, luminaires and parameters of lighting. The instrumentation at the Institute of power and applied electrical engineering STU comprise: photometric bench, photometric integrator $\varnothing 3 \mathrm{~m}$, two mirror type goniophotometers (manual and automatic control), other type goniophotometers, spectrophotometer, luminance meter, luminance analyzer, precise luxmeters, power network analyzers, thermovision camera and others. Automatic goniophotometer and the photometric integrator are made by hand with involvment of students who learn this way to develop measurement instruments.

b) Research Centre of Light and Lighting: Joint venture of the OMS Ltd., Slovak University of Technology and Slovak Academy of Science (Institute of Physics). Students of STU have through this joint venture access to the most advanced instruments and equipment. These are possessed by individual partners but stored at the Centre in Dojč (near Senica, western Slovakia). Selected instruments and equipment: advanced 3D printer, precise luxmeters with different photometric heads, equipment for measurement of reflectance and transmittance (2 integrators and two goniometers on two benches), luminance meter for roadlighting (elliptic), precise luminance analyzer etc.
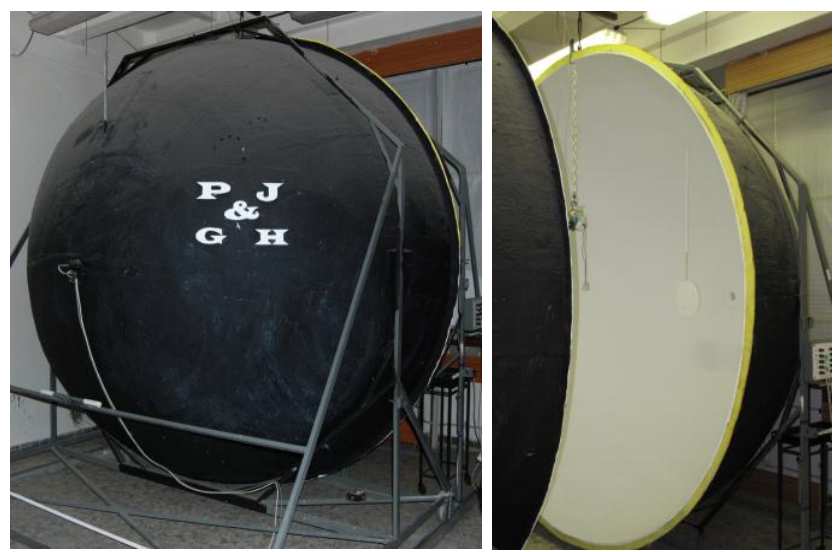

Fig.3. Large photometric integrator $\varnothing 3 \mathrm{~m}$ at the Slovak University of Technology

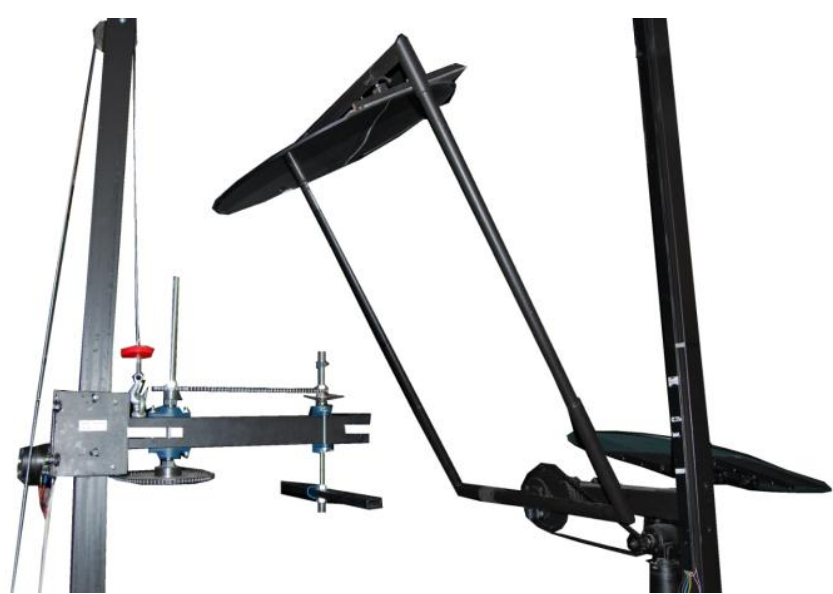

Fig.4. Automated hand-made mirror type goniophotometer at the Slovak University of Technology

\section{Conclusions}

Education of lighting engineers is well established for the needs of the region. Curricula are updated to the stateof-the-art. Complex dedicated study programme suits for preparation of high-level professionals However, the university has to compete to attract the best students. Level of research is in line with current trends in the field of lighting. Laboratories are equipped to have appropriate and up-to-date instrumentation, although there still are significant gaps that need to be covered, the problem is also to sustain the level.

STU offers the new study programme in lighting also in English language what may be attractive for the whole European region and also overseas.

\section{Acknowledgements}

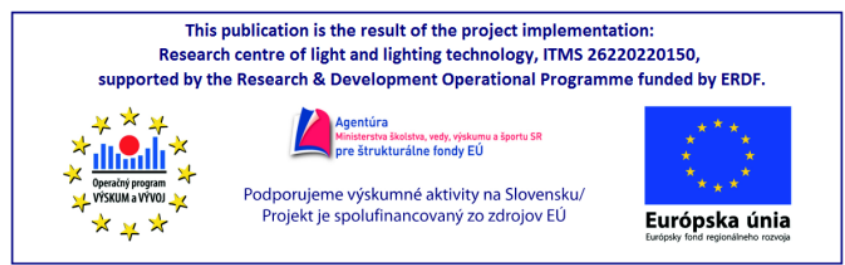

\section{REFERENCES}

[1] JULIAN, W.G.: The Need for Lighting Education. Seventh International Conference on Education and Training in Optics and Photonics, Proceedings of SPIE Vol. 4588 (2002)

[2] DOMALIP, K.: On the Lighting Electrical. Textbook for students (1894/1895).Reissued by Czech Lighting Society (2007)

Authors: Doc. Ing. Dionýz GAŠPAROVSKÝ, PhD., Slovak University of Technology, Faculty of Electrical Engineering and Information Technology, Ilkovicova 3, 81219 Bratislava, Slovakia, e-mail: dionyz.gasparovsky@stuba.sk 